\title{
Long-term pozzolanic reaction of fly ash in hardened cement-based paste internally activated by natural injection of saturated $\mathrm{Ca}(\mathrm{OH})_{2}$ solution
}

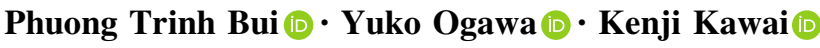

Received: 10 April 2018/Accepted: 15 October 2018/Published online: 19 October 2018

(C) The Author(s) 2019, corrected publication April 2019

\begin{abstract}
The pozzolanic reaction of fly ash in hardened cement-based paste internally activated by a natural injection of saturated $\mathrm{Ca}(\mathrm{OH})_{2}$ solution from the age of 1 month was investigated. This investigation was conducted with the aim of comprehensively evaluating the long-term effectiveness of this technique. The $\mathrm{Ca}(\mathrm{OH})_{2}$ content, degree of the fly-ash reaction, and pore structure were measured using thermal gravimetric analysis, selective dissolution, and mercury intrusion porosimetry, respectively. The $\mathrm{Ca}(\mathrm{OH})_{2}$ consumption was calculated from the $\mathrm{Ca}(\mathrm{OH})_{2}$ content in the pastes with 0 and $40 \%$ replacements of cement by fly ash. The cement hydration and pozzolanic reactions of fly ash in the
\end{abstract}

The original version of this article was revised due to a retrospective Open Access order.

Electronic supplementary material The online version of this article (https://doi.org/10.1617/s11527-018-1274-0) contains supplementary material, which is available to authorized users.

\section{P. T. Bui}

Department of Construction Materials, Faculty of Civil Engineering, Ho Chi Minh City University of Technology, VNU-HCM, 268 Ly Thuong Kiet, Ho Chi Minh City, Vietnam

Y. Ogawa · K. Kawai $(\square)$

Department of Civil and Environmental Engineering,

Hiroshima University, Kagamiyama 1-4-1,

Higashi-Hiroshima 739-8527, Japan

e-mail: kkawai@hiroshima-u.ac.jp pastes proceeded gradually up to 12 months, but were negligible from 12 to 24 months regardless of whether solution was injected. An injection of alkali solution increased both the $\mathrm{Ca}(\mathrm{OH})_{2}$ consumption and the degree of the fly-ash reaction after aging for 12 months. The relationship between the $\mathrm{Ca}(\mathrm{OH})_{2}$ consumption and degree of the fly-ash reaction indicated that the injection of alkali solution activated the surface of the fly-ash particles at early ages, whereas the injection of water did not activate these particles but accelerated the cement hydration, which promoted the pozzolanic reaction. The refinement of the pore structure in the pastes confirmed the effectiveness of the solution injection. Consequently, the injection of saturated $\mathrm{Ca}(\mathrm{OH})_{2}$ solution from the age of 1 month directly activated fly-ash particles and accelerated the long-term pozzolanic reaction (i.e., up to 24 months) in hardened cement paste with $40 \%$ replacement by fly ash, although it was not effective in further enhancing the pozzolanic reaction from 12 to 24 months.

Keywords Internal alkali activation $\cdot \mathrm{Ca}(\mathrm{OH})_{2}$ content - Degree of fly-ash reaction - Pore structure . Selective dissolution

\section{Introduction}

The use of fly ash as a partial replacement for Portland cement in cement concrete has been increasing, 
particularly with the aim of developing sustainable concrete technologies [1]. In addition to reducing the significant carbon dioxide emissions from cement production and lowering construction costs [1-4], flyash utilization improves the mechanical properties and durability of concrete, especially at later ages [3, 5-7]; however, the low reactivity and extremely slow reaction rate of fly ash at ambient temperature usually leads to a low strength and slow rate of strength development of cement concrete at early ages $[3,8]$.

Several methods have been suggested to overcome these drawbacks, including alkali activation, hightemperature curing, a reduction of the water-tocementitious materials ratio $(\mathrm{w} / \mathrm{cm})$, internal water curing, and internal alkali activation [1, 8-17]. Alkali activation on fly ash particles is a chemical procedure in which fly ash is mixed directly with certain alkali activators (alkali solutions), and the mixture is cured at higher-than-ambient temperatures (usually $40-100{ }^{\circ} \mathrm{C}$ ) to accelerate the strength development $[10,11]$. Nevertheless, high-temperature curing is partially limited in terms of practical application [11]. A reduction of $w / c m$ significantly increases the compressive strength but results in early-age cracking of cement pastes containing fly ash $[11,12]$. Internal curing using reservoirs, via pre-wetted lightweight aggregate, super-absorbent polymers, and roof-tile waste aggregate is therefore recommended to reduce autogenous shrinkage and cracking at early ages and to improve the mechanical properties of fly-ash concrete with a low w/cm [12-15].

Bui et al. [16] suggested the use of internal alkali activation (IAA) based on a combined method of alkali activation and internal curing: IAA was carried out at $20{ }^{\circ} \mathrm{C}$ by the natural injection of alkali solution [e.g., $\mathrm{NaOH}$ or saturated $\mathrm{Ca}(\mathrm{OH})_{2}$ solution] into cement-based pastes with 0 and $40 \%$ replacements by fly ash from the age of 1 month. To inject the alkali solution, the tip of a syringe needle was inserted into the center of 40-mm cubic paste specimens as an original model for IAA. A similar system was used for the injection of water as an original model for internal water curing (IWC). The measurement of $\mathrm{Ca}(\mathrm{OH})_{2}$ content, calculation of consumption of $\mathrm{Ca}(\mathrm{OH})_{2}$, and an analysis of the pore structure were carried out shortly after injection. Compared to the case when no solution is injected, IAA using saturated $\mathrm{Ca}(\mathrm{OH})_{2}$ solution from the age of 1 month reduced the $\mathrm{Ca}(\mathrm{OH})_{2}$ content at the tip of the needle but increased the
$\mathrm{Ca}(\mathrm{OH})_{2}$ content at other depths in the cement-based paste containing fly ash at just 1 month after injection. The effect of IWC on the reduction of $\mathrm{Ca}(\mathrm{OH})_{2}$ content at the tip of the needle was not shown clearly. The pore structures at the age of 2 months also confirmed the effectiveness of IAA from the age of 1 month [16]. Meanwhile, IAA from the age of 1 month limited the production of $\mathrm{Ca}(\mathrm{OH})_{2}$ in the cement paste containing no fly ash at 2 months. This may occur because it is difficult for the cement paste to release $\mathrm{Ca}$ ions to the outside because of the high alkali concentration of pore solution supplied from IAA [16].

IAA from the age of 3 months has been also investigated to limit the negative effect of IAA from the age of 1 month on the production of $\mathrm{Ca}(\mathrm{OH})_{2}$ from the cement hydration in pastes at an early age. It was concluded that IAA from the age of 3 months was more effective in accelerating the pozzolanic reaction of fly ash (up to 12 months) in hardened cement-based paste than IWC from the age of 3 months [17].

Generally, previous studies found IAA from the age of 1 month to be effective for accelerating the pozzolanic reaction of fly ash by reducing the $\mathrm{Ca}(\mathrm{OH})_{2}$ content and total pore volume, for increasing the consumption of $\mathrm{Ca}(\mathrm{OH})_{2}$, and for changing of the pore size distributions in cement-based pastes at an age of 2 months. Similar benefits are found at the age of 12 months in the case of IAA from the age of 3 months. However, the degree of the fly-ash reaction in internally alkali-activated cement-based paste containing fly ash has not been investigated. The longterm (i.e., more than 12 months) effect of IAA from the age of 1 month on the pozzolanic reaction of fly ash in cement-based paste has also not been discussed.

The present study focused on a comprehensive evaluation of the effect of IAA on the long-term pozzolanic reaction of fly ash (i.e., up to 24 months) in hardened cement-based paste that was internally activated by the natural injection of saturated $\mathrm{Ca}(\mathrm{OH})_{2}$ solution from the age of 1 month. This injection was carried out through an attached syringe needle that is considered to be an original model of IAA by using reservoirs on fly-ash concrete. The $\mathrm{Ca}(\mathrm{OH})_{2}$ content, consumption of $\mathrm{Ca}(\mathrm{OH})_{2}$, degree of the fly-ash reaction, and the pore structure of the specimen were considered. The correlations between the degree of the fly-ash reaction and consumption of $\mathrm{Ca}(\mathrm{OH})_{2}$ by the pozzolanic reaction were also established. 


\section{Experimental}

\subsection{Materials}

High-early-strength Portland cement (Taiheiyo Cement Corp., Tokyo, Japan) conforming to the Japanese Industrial Standard JIS R 5210 (Portland cement) was used as the main cementitious material to ensure strength, especially at early ages. Low-calcium fly ash (Chugoku Electric Power Co., Inc., Hiroshima, Japan) conforming to JIS A 6201 (fly ash for use in concrete) was also used as a cementitious material to promote its utilization in developing sustainable concrete. The mineralogical compositions of the fly ash, as identified by X-ray diffraction analysis (D2 Phaser, Bruker, AXS K.K., Germany), were $\alpha$-quartz $\left(\mathrm{SiO}_{2}\right)$, mullite $\left(3 \mathrm{Al}_{2} \mathrm{O}_{3} \cdot 2 \mathrm{SiO}_{2}\right)$, hematite $\left(\mathrm{Fe}_{2} \mathrm{O}_{3}\right)$, and magnesioferrite $\left(\mathrm{Fe}_{2} \mathrm{MgO}_{4}\right)$, as seen in Fig. 1. The densities and Blaine specific surface areas of the cement and fly ash were 3.14 and $2.21 \mathrm{~g} / \mathrm{cm}^{3}$, and 4590 and $3290 \mathrm{~cm}^{2} / \mathrm{g}$, respectively. Their chemical compositions are listed in Table 1.

\subsection{Mixture proportion}

Paste specimens were prepared with a low w/cm of 0.30 , for which internal curing would be beneficial [12]. Low-calcium fly ash was used to replace portions of the Portland cement at mass proportions of $0 \%$ ( $\mathrm{Fa} 0)$ and $40 \%(\mathrm{Fa} 40)$.

The temperatures of the materials, mixer, and mold were maintained at $20{ }^{\circ} \mathrm{C}$ during the mixing process. The pastes were mixed in a mechanical mixer and cast in 40-mm-per-side cube-shaped molds. Similar to the experimental method of previous studies [16, 17], a needle with an internal diameter of $0.395 \mathrm{~mm}$ was

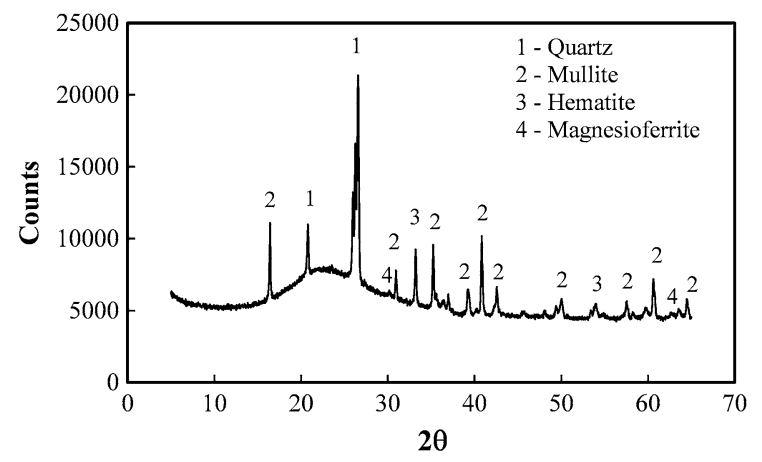

Fig. 1 XRD data of low-calcium fly ash inserted into the center of the specimen. The surfaces were then sealed with aluminum adhesive tape to prevent water loss and carbonation. All specimens were demolded for $24 \mathrm{~h}$ after casting and cured under sealed conditions at $20{ }^{\circ} \mathrm{C}$.

\subsection{Method of internal alkali activation}

Saturated $\mathrm{Ca}(\mathrm{OH})_{2}$ solution as an alkali activator was supplied in the specimen from the age of 1 month through a needle from an attached 1-mL syringe, labeled as IAA- $\mathrm{Ca}(\mathrm{OH})_{2}$ and considered to represent a model of IAA (see Fig. 2). Reference and IWC specimens, fabricated with no solution injection and with water injection, respectively, were similarly prepared. Table 2 lists the cumulative volume of solution that flowed into the specimens with time, which enabled a comparison with the volume of solution released from the reservoirs into the concrete with time. These volumes (cumulative amounts of water from the initial injection to the designated measuring time) varied depending on the individual differences in the microstructures of the different specimens. It means that the volume of solution flowing into each specimen increased with time. However, each value shown in Table 2 was the cumulative volume of solution flowing into each individual specimen at each age of measuring. Therefore, the increase in the volume with time was not observed in Table 2. For example, Fa40 specimens consumed less solution at 12 months than others at 6 months, while $\mathrm{Fa} 0$ specimens consumed less solution at 24 months than others at 12 months. This may be attributed to different microstructures at the point of the syringe needle in these specimens, which may have partially hindered water from flowing into these specimens. Refer to the supplementary file as "Online Resource" for a clear explanation why the cumulative volume of solution flowing into each specimen decreased with time at some data points as shown in Table 2.

It could be expected that alkali and water from the IAA model would naturally flow into the permeable paste specimen, while only water from the IWC model would seep into that specimen. Water plays a role in internal curing because it is needed for the hydration of cementitious materials. Alkali from saturated $\mathrm{Ca}(\mathrm{OH})_{2}$ solution acts as an alkali activator, corroding the chemically stable glassy surface of fly ash and 
Table 1 Chemical compositions of materials (mass\%)

\begin{tabular}{lllrllllll}
\hline Compositions & $\mathrm{SiO}_{2}$ & $\mathrm{Fe}_{2} \mathrm{O}_{3}$ & $\mathrm{Al}_{2} \mathrm{O}_{3}$ & $\mathrm{CaO}$ & $\mathrm{MgO}$ & $\mathrm{SO}_{3}$ & $\mathrm{Na}_{2} \mathrm{O}$ & $\mathrm{K}_{2} \mathrm{O}$ & LOI \\
\hline Cement & 20.30 & 2.71 & 4.96 & 65.49 & 1.21 & 2.98 & 0.22 & 0.35 & 1.19 \\
Fly ash & 57.7 & 5.43 & 27.54 & 1.26 & 1.06 & 0.36 & 0.44 & 0.76 & 2.8 \\
\hline
\end{tabular}

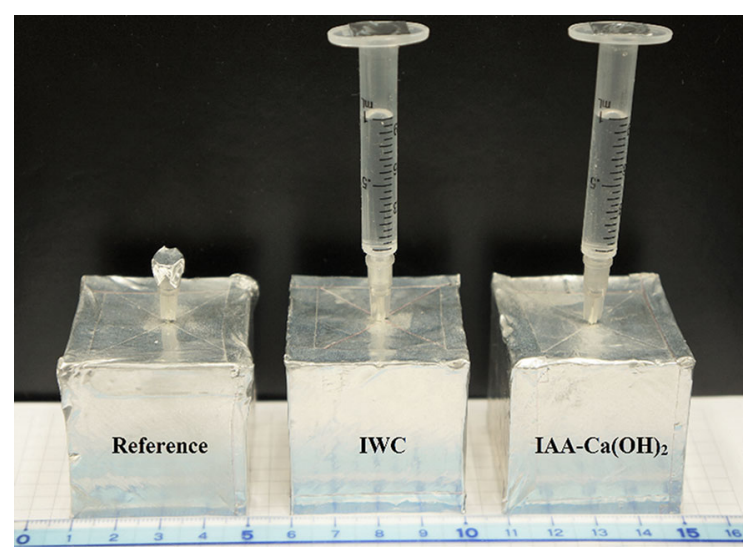

Fig. 2 Cubic paste specimens: reference without solution injection, IWC with water injection, and IAA-Ca(OH $)_{2}$ with injection of saturated $\mathrm{Ca}(\mathrm{OH})_{2}$ solution from age of 1 month

Table 2 Cumulative volume of solution flowing into specimens with time $(\mathrm{mL})$

\begin{tabular}{llllll}
\hline Age (months) & $\mathrm{Fa}$ & & & $\mathrm{Fa} 40$ \\
\cline { 2 - 3 } \cline { 5 - 6 } & Water & $\mathrm{Ca}(\mathrm{OH})_{2}$ & & Water & $\mathrm{Ca}(\mathrm{OH})_{2}$ \\
\hline 2 & 0.10 & 0.10 & & 0.05 & 0.05 \\
4 & 0.26 & 0.26 & & 0.05 & 0.05 \\
6 & 0.38 & 0.40 & & 0.35 & 0.36 \\
12 & 0.57 & 0.65 & & 0.20 & 0.31 \\
24 & 0.55 & 0.27 & & 0.10 & 0.41 \\
\hline
\end{tabular}

$\mathrm{Ca}(\mathrm{OH})_{2}$ : saturated $\mathrm{Ca}(\mathrm{OH})_{2}$ solution

dissociating the $\mathrm{Si}-\mathrm{O}-\mathrm{Si}$ and $\mathrm{Si}-\mathrm{O}-\mathrm{Al}$ links, enabling the main components of fly ash [i.e., $\mathrm{Si}$ and $\mathrm{Al}$ ions] to leach and react with alkali activator to form reaction products $[18,19]$. This is known as the pozzolanic reaction of fly ash.

\subsection{Test procedures}

At each designated age, the $\mathrm{Ca}(\mathrm{OH})_{2}$ content, degree of the fly-ash reaction, and pore structure of each specimen for each case $(n=1)$ [i.e., Reference, IWC, and $\left.\mathrm{IAA}-\mathrm{Ca}(\mathrm{OH})_{2}\right]$ were examined.

\subsection{1 $\mathrm{Ca}(\mathrm{OH})_{2}$ content}

The $\mathrm{Ca}(\mathrm{OH})_{2}$ content in various specimens was measured using a simultaneous differential thermal analysis and thermal gravimetric apparatus (DTG$60 \mathrm{H}$, Shimadzu Corporation, Japan) after aging for 2, 4, 6, 12, and 24 months. A 4-mm section of each sample was drilled out and collected as powder with a particle size smaller than $150 \mu \mathrm{m}$, as shown in Fig. 3 . All samples were soaked in ethanol for $24 \mathrm{~h}$ to avoid any further hydration and were subsequently dried in a vacuum desiccator for $24 \mathrm{~h}$ before thermal gravimetric analysis. The $\mathrm{Ca}(\mathrm{OH})_{2}$ content in each specimen was calculated from the mass of the sample after ignition and the mass loss attributed to dehydration of the $\mathrm{Ca}(\mathrm{OH})_{2}$. This mass loss was determined from a differential thermogravimetry (DTG) plot between the initial and final temperatures of the corresponding DTG peaks [20].

\subsubsection{Degree of fly-ash reaction}

A hydrated sample for testing the degree of the fly-ash reaction was taken from a mixture of samples drilled out from the tip of the needle at a depth of 0-16 $\mathrm{mm}$. The sample was soaked in ethanol for $24 \mathrm{~h}$ to avoid any further hydration and dried in a vacuum desiccator for $24 \mathrm{~h}$ before determining the degree of the fly-ash reaction. This was determined based on a selective dissolution method using $2 \mathrm{M} \mathrm{HCl}$ and $5 \% \mathrm{Na}_{2} \mathrm{CO}_{3}$ aqueous solution [21, 22] and was calculated using Eq. (1):

$\alpha=1-\frac{x\left(1-I_{g}^{\prime}\right) / k_{2}}{\left(1-I_{g}\right) k_{1}}$,

where $\alpha$ is the reaction ratio; $x$ is the extracted residue of the hydrated fly ash in a 1-g hydrated sample 


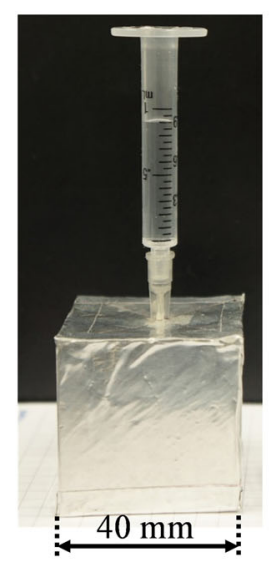

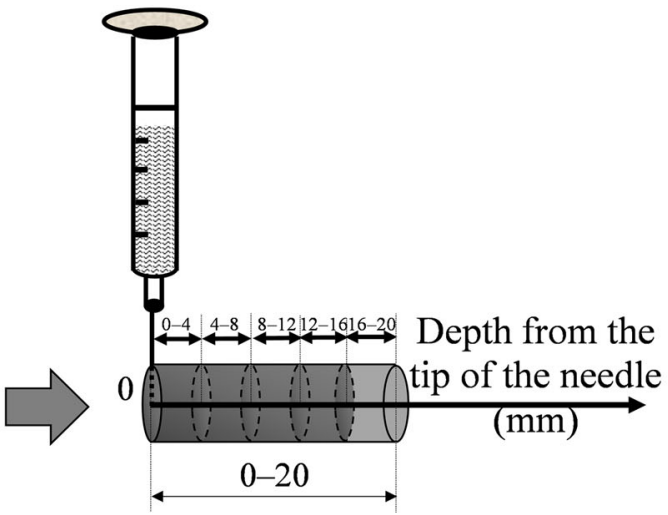

Powder with a particle size smaller than $150 \mu \mathrm{m}$

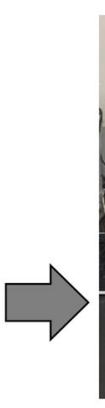

Simultaneous differential thermal analysis and thermal gravimetric apparatus

Fig. 3 Location of samples taken for measuring $\mathrm{Ca}(\mathrm{OH})_{2}$ content using simultaneous differential thermal analysis and thermal gravimetric apparatus

(fraction); $x\left(1-I_{g}^{\prime}\right) / k_{2}$ is the amount (ignited base) of unreacted fly ash in a 1-g hydrated sample; $\left(1-I_{g}\right) k_{1}$ is the total amount (ignited base) of reacted and unreacted fly ash in a 1-g hydrated sample; $I_{g}$ and $I_{g}^{\prime}$ are the losses on ignition of the hydrated sample and extracted residue, respectively (fraction); and $k_{2}$ and $k_{1}$ are the residues extracted from a $1-\mathrm{g}$ fly ash (fraction) and the original fraction of fly ash in the ignited base, respectively.

\subsubsection{Pore structure}

The pore structures of the test specimens were assessed using mercury intrusion porosimetry (MIP). Samples for MIP testing were obtained by crushing the hardened paste cubes within a range of approximately $10 \mathrm{~mm}$ from the tip of the syringe needle and selecting material in a size range of 2.5-5.0 $\mathrm{mm}$. Samples were soaked in ethanol for $24 \mathrm{~h}$ to avoid any further hydration and were dried in a vacuum desiccator for $24 \mathrm{~h}$ before MIP measurements. The mercury intrusion porosimeter (POREMASTER 60, Quantachrome Instrument, Florida, USA) was operated at a maximum pressure of $4.14 \times 10^{8} \mathrm{~N} / \mathrm{m}^{2}$. Individual measurements $(n=1)$ of pore structures in the pastes were performed over a diameter range of $0.003-10 \mu \mathrm{m}$ after aging for 2, 4, 6, 12, and 24 months.

\section{Results and discussion}

3.1 Variation in $\mathrm{Ca}(\mathrm{OH})_{2}$ content with time

\subsubsection{Within a depth of $0-4 \mathrm{~mm}$ from the tip of the needle inserted in specimens}

The $\mathrm{Ca}(\mathrm{OH})_{2}$ contents in hardened cement-based pastes within a depth of $0-4 \mathrm{~mm}$ from the tip of the needle for all cases [Reference, IWC, and IAA$\mathrm{Ca}(\mathrm{OH})_{2}$ ] with time are given in Fig. 4 to express the effect of IAA- $\mathrm{Ca}(\mathrm{OH})_{2}$ on the cement hydration and pozzolanic reaction of fly ash with time. It is noted here that the results for the $\mathrm{Ca}(\mathrm{OH})_{2}$ content at

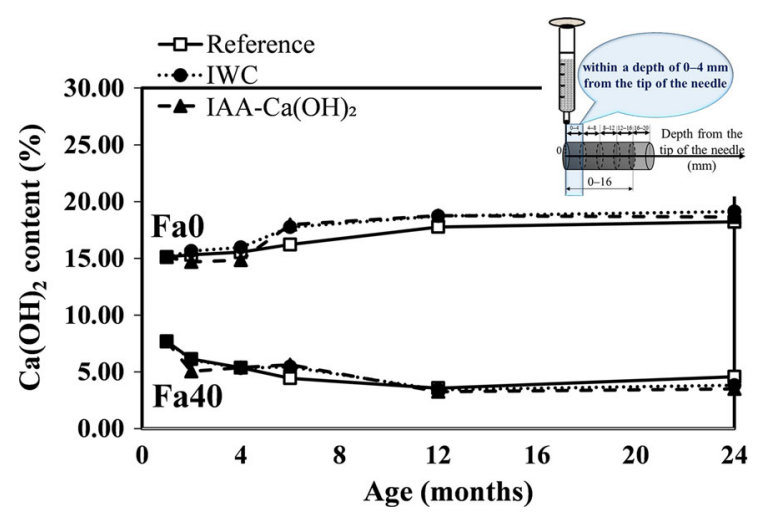

Fig. $4 \mathrm{Ca}(\mathrm{OH})_{2}$ content with time in hardened cement-based pastes within a depth of $0-4 \mathrm{~mm}$ from the tip of the needle inserted in the centers of the $\mathrm{Fa} 0$ and $\mathrm{Fa} 40$ specimens for all cases [Reference, IWC, and IAA-Ca(OH) 2 ] 
2 months were reported in a previous study [16]. Generally, cement pastes containing fly ash have much lower $\mathrm{Ca}(\mathrm{OH})_{2}$ content than those without fly ash $[20,23,24]$. The lower $\mathrm{Ca}(\mathrm{OH})_{2}$ content shown in Fig. 4 is attributed to the partial replacement of cement by low-calcium fly ash.

The $\mathrm{Ca}(\mathrm{OH})_{2}$ content within this depth of the $\mathrm{Fa} 0$ specimen increased with time, regardless of whether solution was injected, from $15.12 \%$ at 1 month to $17.77-18.77 \%$ at 12 months and $18.21-19.11 \%$ at 24 months. It was evident that cement hydration proceeded continuously with time despite using a high-early-strength Portland cement. Cement hydration occurred continuously from 12 to 24 months. For the Fa40 specimens, the $\mathrm{Ca}(\mathrm{OH})_{2}$ content within this depth decreased with time, from $7.69 \%$ at the age of 1 month to $3.26-3.57 \%$ at 12 months and $4.57-3.50 \%$ at 24 months. The reduction in the $\mathrm{Ca}(\mathrm{OH})_{2}$ content appeared to indicate the pozzolanic activity of fly ash $[20,23,25]$. It was concluded that the pozzolanic reaction of fly ash in the Fa40 specimen within this depth proceeded continuously up to 12 months regardless of whether solution was injected but occurred very slowly from 12 to 24 months.

When compared with the Reference, IWC promoted cement hydration in $\mathrm{Fa} 0$ specimens not only at 2 months [16] but also up to 24 months. This results in an increase in the $\mathrm{Ca}(\mathrm{OH})_{2}$ content. By contrast, IAA$\mathrm{Ca}(\mathrm{OH})_{2}$ adversely affected cement hydration in $\mathrm{Fa} 0$ specimens at early ages (i.e., at 2 months, as reported in the previous study [16], and at 4 months), but promoted hydration at later ages (after aging for 6 months), as shown in Fig. 4. Bui et al. [16] explained that the negative effect of the production of $\mathrm{Ca}(\mathrm{OH})_{2}$ in plain cement-based paste at early age was a result of the high concentration of saturated $\mathrm{Ca}(\mathrm{OH})_{2}$ solution injected from the age of 1 month. It may also be expected that this injection will promote cement hydration in Fa40 specimens, resulting in the slightly higher $\mathrm{Ca}(\mathrm{OH})_{2}$ content in $\mathrm{Fa} 40$ specimens up to 24 months. However, the $\mathrm{Ca}(\mathrm{OH})_{2}$ contents in the IWC specimens were nearly the same as those of the Reference at 2, 4, and 12 months, but lower than that of the Reference at 24 months. The $\mathrm{Ca}(\mathrm{OH})_{2}$ contents in the $\mathrm{Fa} 40$ specimens for IAA-Ca $(\mathrm{OH})_{2}$ were lower than those of the Reference at 2 months, slightly lower at 4 and 12 months, and significantly lower at 24 months, despite having higher $\mathrm{Ca}(\mathrm{OH})_{2}$ content at 6 months, as shown in Fig. 4.
In brief, for hardened cement-based paste within a depth of $0-4 \mathrm{~mm}$ from the tip of the needle, IWC promoted cement hydration in the short term (i.e., just 1 month after injection) and accelerated the long-term pozzolanic reaction of fly ash (i.e., 11 and 23 months after injection). IAA-Ca(OH $)_{2}$ adversely affected cement hydration at 1 and 3 months after injections, but promoted cement hydration from 5 to 23 months after injection, in addition to accelerating the pozzolanic reaction of fly ash.

\subsubsection{Within a depth of 0-16 $\mathrm{mm}$ from the tip of the needle}

The $\mathrm{Ca}(\mathrm{OH})_{2}$ content of the entire specimen within a depth of 0-16 $\mathrm{mm}$ from the tip of the needle is given in Fig. 5 for a comprehensive evaluation of the effect of IAA- $\mathrm{Ca}(\mathrm{OH})_{2}$ on the $\mathrm{Ca}(\mathrm{OH})_{2}$ content in both $\mathrm{Fa} 0$ and Fa40 specimens. Previous studies suggested that the $\mathrm{Ca}(\mathrm{OH})_{2}$ content at a depth of $16-20 \mathrm{~mm}$ from the tip of the needle could be influenced by a wall effect because of the mold and aluminum adhesive tape $[16,17]$. Therefore, the $\mathrm{Ca}(\mathrm{OH})_{2}$ content of the entire specimen was calculated as average values at four depths (i.e., at depths of $0-16 \mathrm{~mm}$ from the tip of the needle in increments of $4 \mathrm{~mm})$. The lower $\mathrm{Ca}(\mathrm{OH})_{2}$ content in the entire Fa40 specimen compared with that of the entire $\mathrm{FaO}$ specimen is also described in Fig. 5.

The $\mathrm{Ca}(\mathrm{OH})_{2}$ content in the entire $\mathrm{Fa} 0$ specimen increased with time, from $14.57 \%$ at 1 month to $17.73-18.59 \%$ at 12 months and $18.22-18.83 \%$ at 24 months, regardless of whether solution was

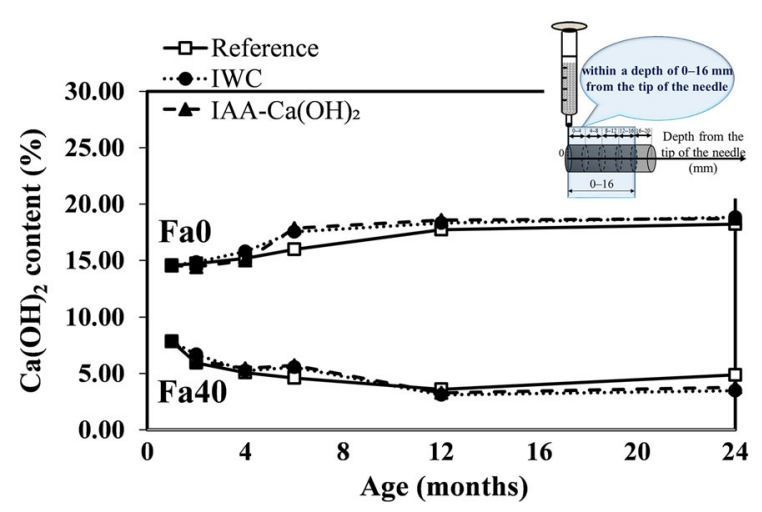

Fig. $5 \mathrm{Ca}(\mathrm{OH})_{2}$ content with time in entire $\mathrm{FaO}$ and $\mathrm{Fa} 40$ specimens within depth of $0-16 \mathrm{~mm}$ from tip of needle for all cases [Reference, IWC, and IAA-Ca(OH) 2 ] 
injected. By contrast, the $\mathrm{Ca}(\mathrm{OH})_{2}$ content in the entire Fa40 specimen decreased with time, from $7.86 \%$ at 1 month to $3.11-3.60 \%$ at 12 months and $3.47-4.87 \%$ at 24 months, regardless of whether solution was injected. It was concluded that cement hydration was still proceeding gradually in hardened plain cement paste without fly-ash replacement, and the pozzolanic reaction still proceeded slowly in hardened cement paste with $40 \%$ replacement by fly ash, at up to 24 months. Similar findings were reported by Sakai et al. [20]: when using a w/cm of 0.4 , the $\mathrm{Ca}(\mathrm{OH})_{2}$ content formed in ordinary Portland cement paste without fly-ash replacement increased with time from approximately $15 \%$ at 28 days to $19 \%$ at 360 days, but that formed in paste with $40 \%$ replacement by fly ash decreased with time from approximately $12 \%$ at 28 days to $9 \%$ at 360 days. The lower $\mathrm{Ca}(\mathrm{OH})_{2}$ content in the present study can be attributed to the differences in the type of cement and fly-ash reactivity.

Compared with Fig. 4, the effects of IWC and IAA$\mathrm{Ca}(\mathrm{OH})_{2}$ on the $\mathrm{Ca}(\mathrm{OH})_{2}$ content in the entire specimen, as seen in Fig. 5, were slightly different at early ages (i.e., 1 and 3 months after injection). However, their effects were almost the same at later ages (i.e., from 5 to 23 months after injection). That is, IWC increased the $\mathrm{Ca}(\mathrm{OH})_{2}$ content in the $\mathrm{Fa} 0$ specimens at all ages and slightly in the Fa40 specimens at 2, 4, and 6 months, but reduced the $\mathrm{Ca}(\mathrm{OH})_{2}$ content in the Fa40 specimens slightly at 12 months and significantly at 24 months. IAA$\mathrm{Ca}(\mathrm{OH})_{2}$ adversely affected the production of $\mathrm{Ca}(\mathrm{OH})_{2}$ in the $\mathrm{Fa} 0$ specimens in the short term, as noted in the slight reduction of $\mathrm{Ca}(\mathrm{OH})_{2}$ content at 2 and 4 months, but thereafter significantly increased the $\mathrm{Ca}(\mathrm{OH})_{2}$ content. For the Fa40 specimens, IAA$\mathrm{Ca}(\mathrm{OH})_{2}$ slightly decreased the $\mathrm{Ca}(\mathrm{OH})_{2}$ content at 12 months and significantly at 24 months. This indicated that the solution [water or saturated $\mathrm{Ca}(\mathrm{OH})_{2}$ solution] flowed naturally throughout the entire specimen after aging for 6 months.

In brief, IWC and IAA-Ca $(\mathrm{OH})_{2}$ promoted cement hydration in the entire $\mathrm{Fa} 0$ specimen at later ages, as concluded from the increase in the $\mathrm{Ca}(\mathrm{OH})_{2}$ content after aging for 6 months. In addition to promoting cement hydration in the entire Fa40 specimen, IWC and IAA- $\mathrm{Ca}(\mathrm{OH})_{2}$ accelerated the pozzolanic reaction of fly ash, as seen in the reduction of the $\mathrm{Ca}(\mathrm{OH})_{2}$ content after aging for 12 months. Moreover, the positive effect of IWC and IAA-Ca(OH $)_{2}$ on accelerating the pozzolanic reaction of fly ash in the entire $\mathrm{Fa} 40$ specimen was almost the same, as seen in the reduction of the $\mathrm{Ca}(\mathrm{OH})_{2}$ content at later ages (i.e., after aging for 12 months).

\subsection{Consumption of $\mathrm{Ca}(\mathrm{OH})_{2}$ by pozzolanic reaction of fly ash with time}

Although it has been reported that the degree of cement hydration in paste including cement and fly ash increases more than that in paste containing only cement [26], the present study assumed that cement hydration in the cement-based paste with $40 \%$ replacement by fly ash ( $\mathrm{Fa} 40)$ was the same as that in the plain cement-based paste $(\mathrm{Fa} 0)$. It implies that the $\mathrm{Ca}(\mathrm{OH})_{2}$ produced per unit mass of cement at a given curing time is independent of the hydration environment of the cement. The consumption of $\mathrm{Ca}(\mathrm{OH})_{2}$ by the pozzolanic reaction up to 24 months in Fa40 specimens was therefore calculated by Eq. (2) for all cases:

$\mathrm{CH}_{\text {cons. }}=\mathrm{CH}_{\mathrm{Fa} 0}(c /(c+f))-\mathrm{CH}_{\mathrm{Fa} 40}$,

where $\mathrm{CH}_{\text {cons. }}$ is the consumption of $\mathrm{Ca}(\mathrm{OH})_{2}$ by the pozzolanic reaction (\%); $\mathrm{CH}_{\mathrm{Fa} 0}$ and $\mathrm{CH}_{\mathrm{Fa} 40}$ are the $\mathrm{Ca}(\mathrm{OH})_{2}$ content in $\mathrm{Fa} 0$ and $\mathrm{Fa} 40$ specimens, respectively $(\%)$; and $(c /(c+f))=0.60$ is the mass ratio of cement in the cementitious materials (cement + fly ash).

According to Zhang et al. [25], a negative value of consumptions of $\mathrm{Ca}(\mathrm{OH})_{2}$ calculated by Eq. (2) reveals that extra $\mathrm{Ca}(\mathrm{OH})_{2}$ is formed due to the addition of fly ash, that is, the addition of fly ash accelerates the hydration of cement. However, the negative values were not observed in this study. It indicates that the addition of fly ash has no effect on the hydration of the cement at all.

Regarding the pozzolanic reaction of fly ash in the fly ash-cement system, Sakai et al. [20] reported that fly ash started to react and consume $\mathrm{Ca}(\mathrm{OH})_{2}$ after aging for 28 days. This meant that the consumption of $\mathrm{Ca}(\mathrm{OH})_{2}$ was equal to zero at 28 days. The consumption of $\mathrm{Ca}(\mathrm{OH})_{2}$ in the present study, calculated by Eq. (2), was approximately zero after 1 month because the $\mathrm{Ca}(\mathrm{OH})_{2}$ content of the $\mathrm{Fa} 40$ specimen was approximately $60 \%$ of the $\mathrm{Ca}(\mathrm{OH})_{2}$ content in the $\mathrm{Fa} 0$ specimen at this time, as shown in Figs. 4 and 5. It 
was concluded that Eq. (2) was therefore appropriate for use in the present study.

\subsubsection{Within a depth of $0-4 \mathrm{~mm}$ from the tip of the needle inserted in specimens}

The consumption of $\mathrm{Ca}(\mathrm{OH})_{2}$ by the pozzolanic reaction within a depth of $0-4 \mathrm{~mm}$ from the tip of the needle inserted in the specimens with time is shown in Fig. 6. The consumption of $\mathrm{Ca}(\mathrm{OH})_{2}$ increased with time, from $1.38 \%$ at 1 month to $7.09-8.00 \%$ at 12 months and $6.36-7.69 \%$ at 24 months, regardless of whether solution was injected. It was observed that the consumption of $\mathrm{Ca}(\mathrm{OH})_{2}$ by the pozzolanic reaction within this depth of the Fa40 specimens increased significantly from 1 to 12 months but remained constant from 12 to 24 months regardless of whether solution was injected.

Compared with the Reference, the IWC and IAA$\mathrm{Ca}(\mathrm{OH})_{2}$ specimens increased their consumption of $\mathrm{Ca}(\mathrm{OH})_{2}$ slightly at 2 months and significantly at 12 and 24 months. This confirmed that IWC and IAA$\mathrm{Ca}(\mathrm{OH})_{2}$ were effective in accelerating the pozzolanic reaction of fly ash for the Fa40 specimens for a long period (i.e., 11 and 23 months) after injection. It also appeared that the consumption of $\mathrm{Ca}(\mathrm{OH})_{2}$ within this region of the specimens was slightly lower for IAA$\mathrm{Ca}(\mathrm{OH})_{2}$ than that for the Reference at the age of 4 months. This may be partially attributed to the negative effect of IAA- $\mathrm{Ca}(\mathrm{OH})_{2}$ from 1 month on the

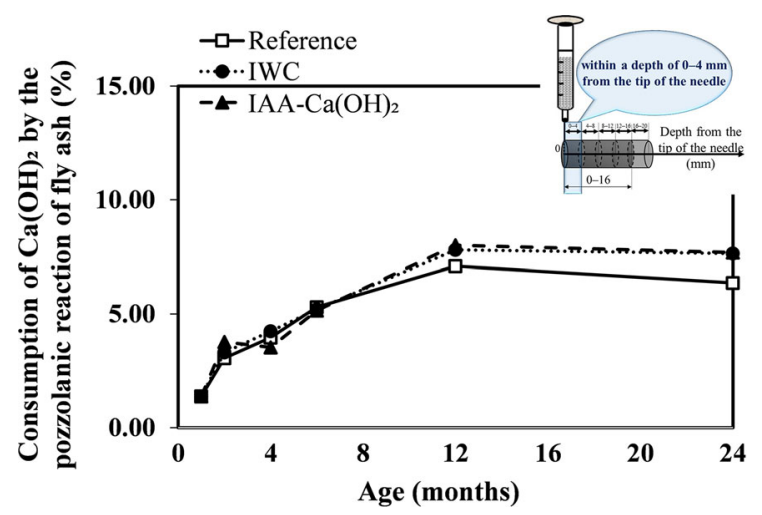

Fig. 6 Consumption of $\mathrm{Ca}(\mathrm{OH})_{2}$ by the pozzolanic reaction of fly ash with time within a depth of $0-4 \mathrm{~mm}$ from the tip of the needle inserted in the center of the Fa40 specimens for all cases [Reference, IWC, and IAA-Ca(OH) 2 ] cement hydration in the $\mathrm{Fa} 0$ specimen at that time, as seen in Fig. 4.

\subsubsection{Within a depth of $0-16 \mathrm{~mm}$ from the tip of the needle inserted in specimens}

Similar to the $\mathrm{Ca}(\mathrm{OH})_{2}$ content, the consumption of $\mathrm{Ca}(\mathrm{OH})_{2}$ by the pozzolanic reaction of fly ash in the entire specimen was defined as the average value obtained within a depth of $0-16 \mathrm{~mm}$ from the tip of the needle, as shown in Fig. 7. The consumption of $\mathrm{Ca}(\mathrm{OH})_{2}$ in the entire specimen increased with time, from $0.88 \%$ at 1 month to $7.04-7.88 \%$ at 12 months and $6.06-7.83 \%$ at 24 months, regardless of whether solution was injected. The increase in the consumption of $\mathrm{Ca}(\mathrm{OH})_{2}$ by the pozzolanic reaction in the entire Fa40 specimen was significant from 1 to 12 months but negligible after aging for 12 months regardless of whether solution was injected.

Compared with the Reference, IWC and IAA$\mathrm{Ca}(\mathrm{OH})_{2}$ showed higher consumption of $\mathrm{Ca}(\mathrm{OH})_{2}$ by the pozzolanic reaction of fly ash at 12 and 24 months but not at 2, 4, or 6 months. The pozzolanic reaction of fly ash in the entire Fa40 specimen internally injected with solution [water or saturated $\mathrm{Ca}(\mathrm{OH})_{2}$ solution] was accelerated significantly at 12 and 24 months; however, this was not observed clearly for IWC and IAA- $\mathrm{Ca}(\mathrm{OH})_{2}$ at aging times of 2, 4, and 6 months. This may be a result of various effects of the injection of solution, including on the cement hydration and flyash reactions, in cement-based systems. This is discussed in Sect. 3.3.

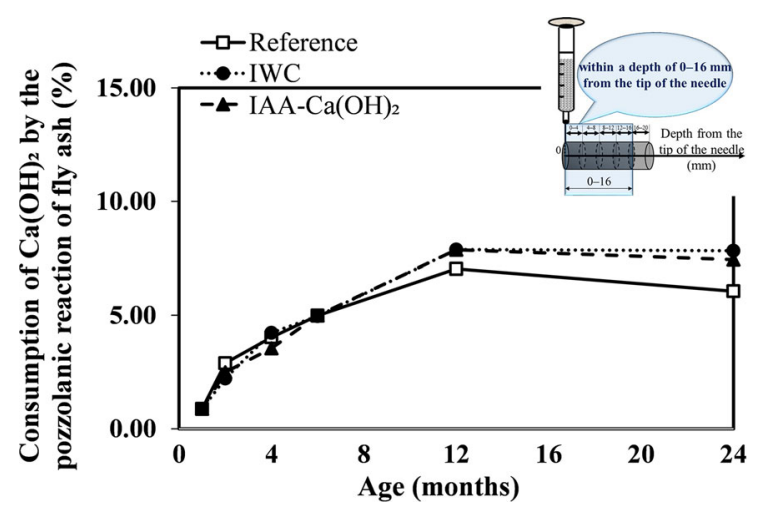

Fig. 7 Consumption of $\mathrm{Ca}(\mathrm{OH})_{2}$ by pozzolanic reaction of fly ash with time in entire Fa40 specimens within depth of 0-16 mm from tip of needle for all cases [Reference, IWC, and $\mathrm{IAA}-\mathrm{Ca}(\mathrm{OH})_{2}$ ] 


\subsection{Degree of fly-ash reaction}

Figure 8 shows the effect of IAA- $\mathrm{Ca}(\mathrm{OH})_{2}$ on the degree of the fly-ash reaction in $\mathrm{Fa} 40$ specimens when compared with those of the Reference and IWC at each age. For the Reference, the degree of the fly-ash reaction in Fa40 specimens increased with time, from $20.2 \%$ at 2 months to $24.3 \%$ at 12 months and $26.3 \%$ at 24 months. According to Lam et al. [23], when using a w/cm of 0.3 , the degree of the fly-ash reaction in cement pastes with 25 and $55 \%$ replacements by fly ash increased from 14.41 to $11.21 \%$ at 28 days to 24.58 and $17.03 \%$ at 90 days, respectively, resulting from an active pozzolanic reaction. This effect was also observed in the present study, indicating an active pozzolanic reaction in the hardened cement-based paste with $40 \%$ replacement by fly ash.

This tendency was also shown for IWC and IAA$\mathrm{Ca}(\mathrm{OH})_{2}$; however, the increase in the degree of the fly-ash reaction in the entire Fa40 specimen from 12 to 24 months was negligible for the three cases [Reference, IWC, and IAA-Ca(OH $\left.)_{2}\right]$. This is similar to the insignificant increase in the consumption of $\mathrm{Ca}(\mathrm{OH})_{2}$ by the pozzolanic reaction of fly ash, as shown in Fig. 7. Sakai et al. [20] also found a negligible increase in the degree of the fly-ash reaction in cement paste with $40 \%$ replacement by fly ash having high glass content and high basicity of glass phase after aging for 270 days. The authors concluded that the glass content and glass phase compositions slightly affect the reaction over long curing periods such as 12 months [20]. It is noted that basicity of fly ash in this study was estimated following the calculation for

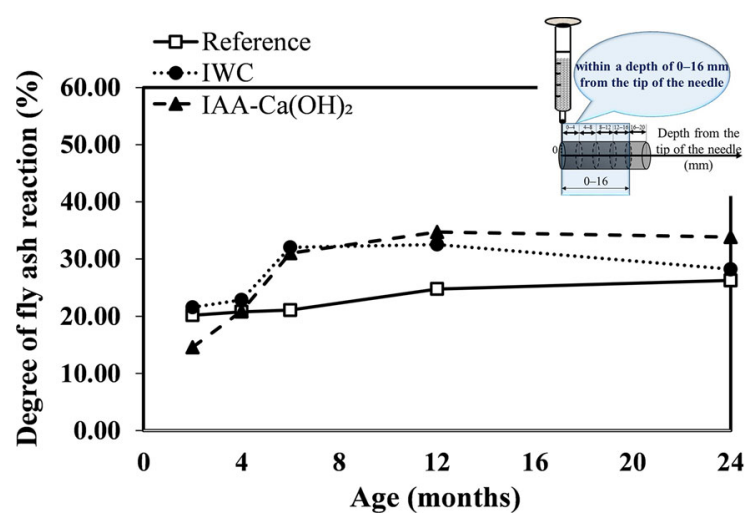

Fig. 8 Degree of fly-ash reaction with time in entire Fa40 specimens for all cases [Reference, IWC, and IAA-Ca $(\mathrm{OH})_{2}$ ] blast furnace slag per Japanese Industrial Standard, i.e., basicity $=\left(\mathrm{CaO}+\mathrm{MgO}+\mathrm{Al}_{2} \mathrm{O}_{3}\right) / \mathrm{SiO}_{2}=0.52$. This value is higher than that of the fly ash used in the study of Sakai et al. (i.e., basicity $=0.40$ ) [20]. Therefore, the negligible increase in the consumption of $\mathrm{Ca}(\mathrm{OH})_{2}$ by the pozzolanic reaction of fly ash and that in the degree of fly ash in this study could be a result of the high basicity of glass phase in fly ash particles.

Compared with the Reference, the degrees of the fly-ash reaction in the IAA-Ca $(\mathrm{OH})_{2}$ and IWC specimens were higher at each age except for IAA$\mathrm{Ca}(\mathrm{OH})_{2}$ at 2 months. The Reference achieved only a $26.3 \%$ reaction at 24 months, while those of IWC and IAA-Ca(OH $)_{2}$ were $28.2 \%$ and $33.8 \%$, respectively. Moreover, significant increases in the degree of the fly-ash reaction for IAA-Ca $(\mathrm{OH})_{2}$ and IWC were observed after aging for 6 months when compared with the Reference. This may be attributed to solution flow throughout the entire $\mathrm{Fa} 40$ specimen. This confirmed that IAA-Ca $(\mathrm{OH})_{2}$ and IWC increased the degree of the fly-ash reaction in the $\mathrm{Fa} 40$ specimens, and significantly at later ages.

It is known that an increase in the degree of the flyash reaction corresponds to a decrease in $\mathrm{Ca}(\mathrm{OH})_{2}$ content and an increase in consumption of $\mathrm{Ca}(\mathrm{OH})_{2}$, indicating an active pozzolanic reaction [23, 27]. Correlations between degree of the fly-ash reaction and consumption of $\mathrm{Ca}(\mathrm{OH})_{2}$ by the pozzolanic reaction in Fa40 specimens are shown in Fig. 9. Regression lines are also shown to evaluate the effects

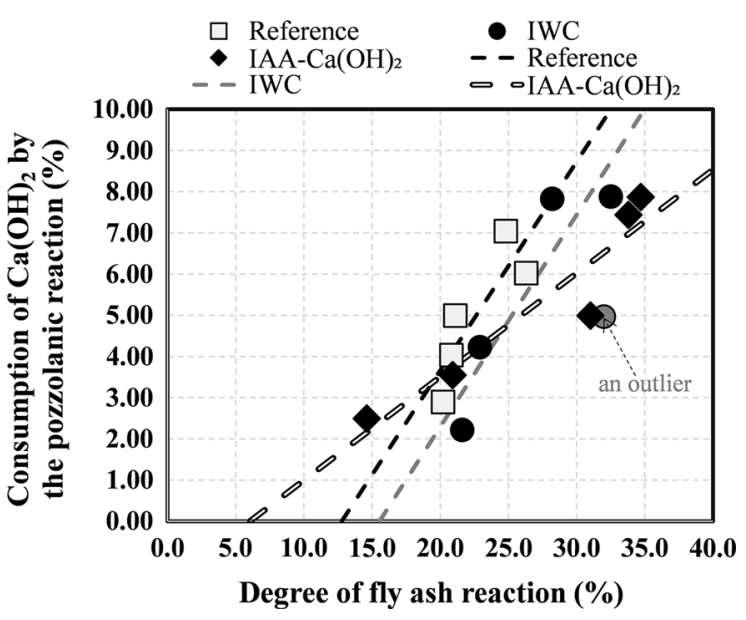

Fig. 9 Correlation between degree of fly-ash reaction and consumption of $\mathrm{Ca}(\mathrm{OH})_{2}$ by pozzolanic reaction 
of the reactions in these systems. [It is noted here that the regression line for IWC was drawn after eliminating the data points of $32.0 \%$ for degree of reaction and $4.97 \%$ for $\mathrm{Ca}(\mathrm{OH})_{2}$ consumption, which were considered outliers (see Fig. 9).]

According to these regression lines, the degree of the fly-ash reaction that started to consume $\mathrm{Ca}(\mathrm{OH})_{2}$ differed between IAA-Ca(OH $)_{2}$ and the other two specimens: $\mathrm{Ca}(\mathrm{OH})_{2}$ started to be consumed at about a $6 \%$ reaction for IAA-Ca $(\mathrm{OH})_{2}$ but at about $12 \%$ and $16 \%$ for Reference and IWC, respectively. This means that below these degrees of reaction for each case, there was no $\mathrm{Ca}(\mathrm{OH})_{2}$ consumption by the pozzolanic reaction of fly ash. It can be said that the starting time of the pozzolanic reaction of fly ash that consumes $\mathrm{Ca}(\mathrm{OH})_{2}$ is the time when the degree of the fly-ash reaction reached $12 \%$ for Reference, $16 \%$ for IWC, and $6 \%$ for IAA- $\mathrm{Ca}(\mathrm{OH})_{2}$. The slope of the regression lines also differed between IAA- $\mathrm{Ca}(\mathrm{OH})_{2}$ and both the Reference and IWC: the slope for IAA-Ca(OH $)_{2}$ was about 0.25 , while that for the Reference and IWC was about 0.51 . It was concluded that IAA- $\mathrm{Ca}(\mathrm{OH})_{2}$ had a lower degree of the fly-ash reaction at which $\mathrm{Ca}(\mathrm{OH})_{2}$ started to be consumed. This is because IAA-Ca $(\mathrm{OH})_{2}$ activated fly-ash particles themselves. However, the consumption of $\mathrm{Ca}(\mathrm{OH})_{2}$ by the pozzolanic reaction in which IAA-Ca $(\mathrm{OH})_{2}$ activated fly-ash particles was comparatively low. Because the pozzolanic reaction produced calcium silicate hydrate from a lower degree of the fly-ash reaction for IAA- $\mathrm{Ca}(\mathrm{OH})_{2}$, the pores became finer from early ages when compared with those of the Reference and IWC. This was confirmed by the pore structure results of Fa40 specimens at 1 month after injection that were reported in a previous study [16].

The degree of the fly-ash reaction at which $\mathrm{Ca}(\mathrm{OH})_{2}$ started to be consumed for IWC was higher than that for the Reference, which implied that IWC did not contribute to activating fly-ash particles; however, the regression line for IWC shifted to the right from that for the Reference, as seen in Fig. 9. Although IWC did not contribute to activating the flyash particles, its pozzolanic reaction proceeded with a lower $\mathrm{Ca}(\mathrm{OH})_{2}$ consumption than that of the Reference once the reaction began. This may be a result of an acceleration of cement hydration. Because the degree of the fly-ash reaction giving a certain $\mathrm{Ca}(\mathrm{OH})_{2}$ consumption for IWC was higher than that for the Reference (see Fig. 9), it was easier for the pores to become finer. This was also confirmed by the pore structure results of the Fa40 specimen 1 month after the injection of water [16]. The pore structure of these specimens 23 months after the injection of solution is discussed in Sect. 3.4 in order to confirm the positive long-term effect of IAA-Ca(OH $)_{2}$ and IWC on the acceleration of the pozzolanic reaction of fly ash after injection.

Briefly, the injection of saturated $\mathrm{Ca}(\mathrm{OH})_{2}$ solution from the age of 1 month activated fly-ash particles, which directly resulted in the acceleration of the pozzolanic reaction. IWC did not contribute to activating fly-ash particles but accelerated cement hydration, which resulted in the acceleration of the pozzolanic reaction of fly ash.

\subsection{Variation in pore structure with time}

\subsubsection{Volume of total pores}

Figure 10 shows the effect of IAA-Ca $(\mathrm{OH})_{2}$ on the volumes of total pores in the $0.003-10 \mu \mathrm{m}$ range in $\mathrm{Fa} 0$ and $\mathrm{Fa} 40$ specimens when compared with the Reference and IWC at 24 months. The volume of the total pores for the Reference at 2 months is shown for comparison. The volumes of the total pores in both the $\mathrm{Fa} 0$ and $\mathrm{Fa} 40$ Reference specimens decreased with time, a result that has been found in previous studies [20, 27-29]. It is known that fly ash decreases the strength, which results from an increase in the volume of pores in paste/concrete [24, 29]. A similar result was also observed in the present study. The cement pastes with $40 \%$ replacement by fly ash $(\mathrm{Fa} 40)$ had a higher volume of total pores than the plain cement pastes $(\mathrm{Fa} 0)$ at each age and for each case [Reference, IWC, and IAA-Ca(OH $)_{2}$.

For the $\mathrm{Fa} 0$ specimens at 24 months, IAA- $\mathrm{Ca}(\mathrm{OH})_{2}$ and IWC reduced the volume of the total pores ranging from 0.003 to $10 \mu \mathrm{m}$ when compared with the Reference by $15.8 \%$ and $15.2 \%$, respectively. For $\mathrm{Fa} 40$ specimens at 24 months, IAA- $\mathrm{Ca}(\mathrm{OH})_{2}$ and IWC slightly reduced the volume of the total pores ranging from 0.003 to $10 \mu \mathrm{m}$ when compared with the Reference by $5.3 \%$ and $1.7 \%$, respectively.

\subsubsection{Pore size distribution}

Figure 11 shows the effect of IAA-Ca $(\mathrm{OH})_{2}$ on the pore size distribution in $\mathrm{Fa} 0$ specimens when 


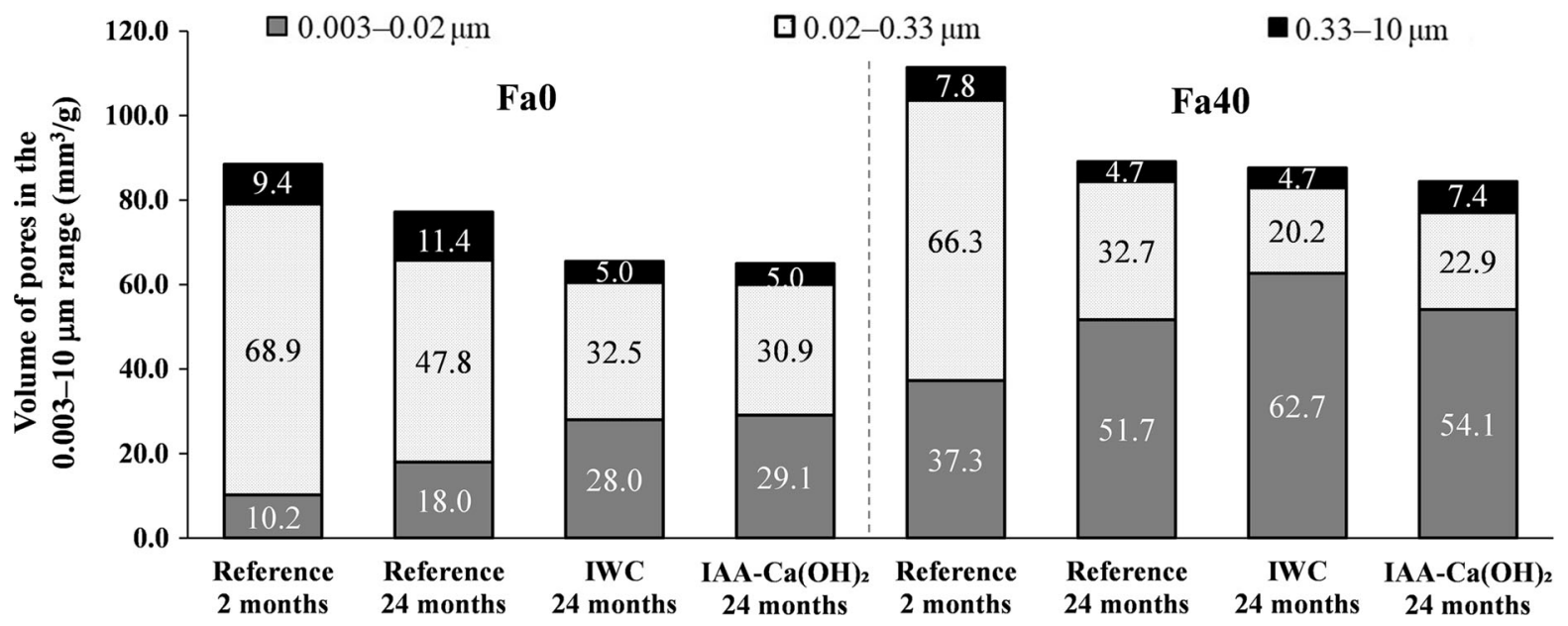

Fig. 10 Volumes of total pores in $\mathrm{Fa} 0$ and $\mathrm{Fa} 40$ specimens at 24 months (i.e., 23 months after injection) for all cases [Reference, IWC, and IAA- $\left.\mathrm{Ca}(\mathrm{OH})_{2}\right]$ compared with those for Reference at 2 months

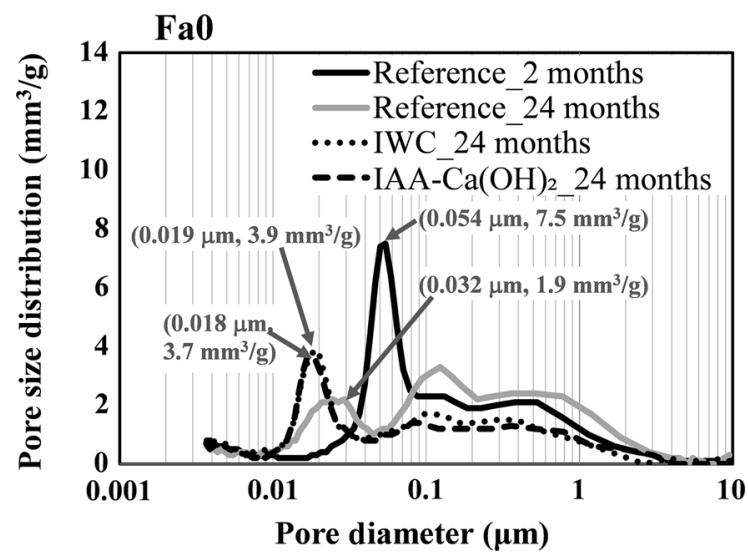

Fig. 11 Pore size distribution in $\mathrm{Fa} 0$ specimens at 24 months (i.e., 23 months after injection) for all cases [Reference, IWC, and IAA-Ca $(\mathrm{OH})_{2}$ ] compared with those for Reference at 2 months

compared with Reference and IWC at 24 months and the Reference at 2 months. There were three peaks: the first and second peaks in the range of $0.1-10 \mu \mathrm{m}$ and the third in the range of $0.003-0.1 \mu \mathrm{m}$. The Reference third peak decreased from $0.054 \mu \mathrm{m}$ with a pore volume of $7.5 \mathrm{~mm}^{3} / \mathrm{g}$ at 2 months to $0.032 \mu \mathrm{m}$ with a pore volume of $1.9 \mathrm{~mm}^{3} / \mathrm{g}$ at 24 months, although the first and second peaks at 24 months were slightly higher than those at 2 months.

Compared with the Reference at 24 months, the first and second peaks in the $0.1-10 \mu \mathrm{m}$ range for IWC and IAA- $\mathrm{Ca}(\mathrm{OH})_{2}$ were much lower, but the third peak in the 0.003-0.1 $\mu \mathrm{m}$ range was higher: $0.019 \mu \mathrm{m}$ with a pore volume of $3.9 \mathrm{~mm}^{3} / \mathrm{g}$ and $0.018 \mu \mathrm{m}$ with a pore volume of $3.7 \mathrm{~mm}^{3} / \mathrm{g}$, respectively. These results suggested that IWC and IAA- $\mathrm{Ca}(\mathrm{OH})_{2}$ affected the pore size distribution at 24 months in the $\mathrm{Fa} 0$ specimen, with a decrease in the volume of pore diameters in the $0.1-10 \mu \mathrm{m}$ range and an increase in the range of $0.003-0.1 \mu \mathrm{m}$. This is attributed to the gradual filling of large pores (i.e., capillary pores) and the formation of small pores (i.e., gel pores) from additional hydration products resulting from the promotion of cement hydration by IWC and IAA-Ca(OH $)_{2}$ at 23 months after injection.

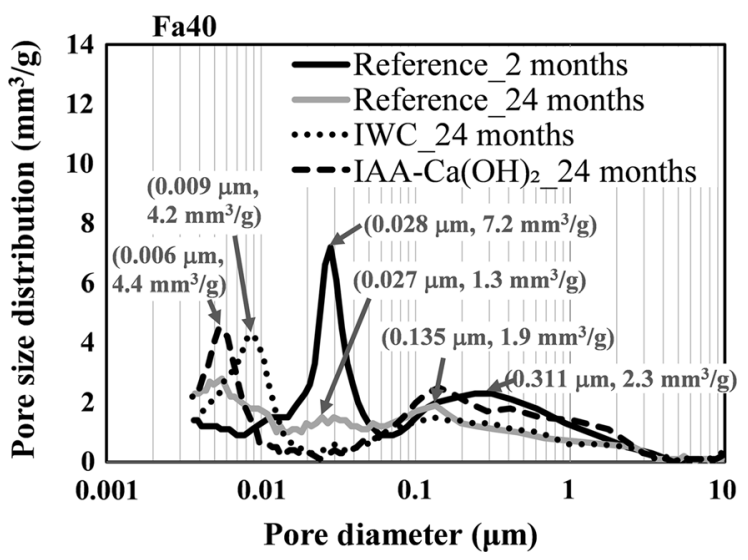

Fig. 12 Pore size distribution in Fa40 specimens at 24 months (i.e., 23 months after injection) for all cases [Reference, IWC, and IAA-Ca(OH $)_{2}$ ] compared with those for Reference at 2 months 
Figure 12 shows the effect of IAA-Ca $(\mathrm{OH})_{2}$ on the pore size distribution in Fa40 specimens when compared with the Reference and IWC at 24 months. The 2-month value for the Reference is given for comparison. The first and second peaks in the $0.02-10 \mu \mathrm{m}$ range were lower for $\mathrm{Fa} 40$ specimens at 24 months than those at 2 months. At 24 months, the first and second peaks of the Reference were located at $0.135 \mu \mathrm{m}$ and $0.027 \mu \mathrm{m}$ with pore volumes of $1.9 \mathrm{~mm}^{3} / \mathrm{g}$ and $1.3 \mathrm{~mm}^{3} / \mathrm{g}$, respectively. These values were lower than those at 2 months, which were located at $0.311 \mu \mathrm{m}$ with a pore volume of $2.3 \mathrm{~mm}^{3} / \mathrm{g}$ for the first peak and $0.028 \mu \mathrm{m}$ with a pore volume of $7.2 \mathrm{~mm}^{3} / \mathrm{g}$ for the second peak. Peaks in the $0.003-0.02 \mu \mathrm{m}$ range for the Reference at 24 months were higher than those at 2 months. These results indicated that the products from cement hydration and the pozzolanic reaction of fly ash in Fa40 specimens formed gradually, filling the large pores and generating small pores in the specimens with time [27].

When compared with the Reference at 24 months, the peaks in the $0.02-10 \mu \mathrm{m}$ range were lower for IWC and IAA- $\mathrm{Ca}(\mathrm{OH})_{2}$, except the first peak for IAA. Peaks in the $0.003-0.02 \mu \mathrm{m}$ range increased to 0.009 $\mu \mathrm{m}$ with a pore volume of $4.2 \mathrm{~mm}^{3} / \mathrm{g}$ for IWC and to $0.006 \mu \mathrm{m}$ with a pore volume of $4.4 \mathrm{~mm}^{3} / \mathrm{g}$ for IAA$\mathrm{Ca}(\mathrm{OH})_{2}$. These results suggested that IWC and IAA$\mathrm{Ca}(\mathrm{OH})_{2}$ also affected the pore size distribution at 24 months in the Fa40 specimens, with a decrease in the volume of pore diameters in the $0.02-10 \mu \mathrm{m}$ range and an increase in the volume of pore diameters in the range of $0.003-0.02 \mu \mathrm{m}$. These resulted from the gradual filling of large pores and the additional formation of small pores from the hydration of cement and the pozzolanic reaction of fly ash, which were promoted by IWC and IAA- $\mathrm{Ca}(\mathrm{OH})_{2}$ at 23 months after injection.

Briefly, IWC and IAA affected the pore size distribution at 24 months in both the $\mathrm{Fa} 0$ and $\mathrm{Fa} 40$ specimens, with a decrease in the volume of large pores and an increase in that of small pores. This is discussed in more detail in Sect. 3.4.3.

\subsubsection{Volume of pores related to pozzolanic reaction}

According to Yamamoto and Kanazu [30], the volume of pores in the $0.02-0.33 \mu \mathrm{m}$ range decreased and that of pores in the $0.003-0.02 \mu \mathrm{m}$ range increased as the pozzolanic reaction of fly ash proceeded. The volumes of these pore ranges are also shown in Fig. 10. For the Reference, the volume ratio of pores in the $0.02-0.33 \mu \mathrm{m}$ range to the total pores decreased with time and that of pores in the $0.003-0.02 \mu \mathrm{m}$ range increased with time regardless of fly-ash replacement.

When compared with Reference, IWC and IAA$\mathrm{Ca}(\mathrm{OH})_{2}$ showed a decrease in the volume proportion of pores in the $0.02-0.33 \mu \mathrm{m}$ range and an increase in that of pores in the $0.003-0.02 \mu \mathrm{m}$ range in the Fa40 specimens at 24 months. Similar findings were reported in previous studies $[16,17]$. The changes in the volume ratios in the Fa40 specimens imply that the pozzolanic reaction of fly ash was accelerated by IAA$\mathrm{Ca}(\mathrm{OH})_{2}$ and IWC. These changes were also shown in specimens at 2, 4, 6, and 12 months. This is compatible with an increase in the degree of the fly-ash reaction for IWC and IAA-Ca(OH $)_{2}$ at all ages [except at 2 months for IAA- $\left.\mathrm{Ca}(\mathrm{OH})_{2}\right]$. The increase in the volume of the pores in the $0.33-10 \mu \mathrm{m}$ range for IAA$\mathrm{Ca}(\mathrm{OH})_{2}$ in the Fa40 specimen shown in Fig. 10 may be due to the exposure of hollow voids in the fly ash into which mercury was intruded.

It was reported that IWC and IAA-Ca $(\mathrm{OH})_{2}$ did not affect these volume ratios in $\mathrm{Fa} 0$ specimens at 2 months (i.e., 1 month after injection) [16]; however, these volume ratios were affected by IWC and IAA$\mathrm{Ca}(\mathrm{OH})_{2}$ at 24 months, as seen in Fig. 10. It was concluded that IWC and IAA- $\mathrm{Ca}(\mathrm{OH})_{2}$ can refine the pore structures in both $\mathrm{Fa} 0$ and $\mathrm{Fa} 40$ specimens at 24 months.

\section{Conclusions}

The long-term pozzolanic reaction of fly ash (i.e., up to 24 months) in hardened cement-based paste internally activated by the natural injection of saturated $\mathrm{Ca}(\mathrm{OH})_{2}$ solution from the age of 1 month was investigated. The results for $\mathrm{Ca}(\mathrm{OH})_{2}$ content, consumption of $\mathrm{Ca}(\mathrm{OH})_{2}$, degree of the fly-ash reaction, and pore structure in pastes internally activated by IAA$\mathrm{Ca}(\mathrm{OH})_{2}$ were compared with those in pastes internally cured by IWC and those in pastes that supplied no solution (Reference). The following conclusions were drawn:

- The effects of IWC and IAA-Ca(OH $)_{2}$ on the $\mathrm{Ca}(\mathrm{OH})_{2}$ content within a depth of $0-16 \mathrm{~mm}$ from the tip of the needle in the entire specimen were 
slightly different from those of IWC and IAA$\mathrm{Ca}(\mathrm{OH})_{2}$ on the $\mathrm{Ca}(\mathrm{OH})_{2}$ content within a depth of 0-4 $\mathrm{mm}$ from the tip of the needle at 2 and 4 months. However, their effects were nearly the same from 6 to 24 months. This indicated that the solution moved completely into the entire specimen after aging for 6 months.

- Cement hydration proceeded gradually, and the pozzolanic reaction of fly ash in hardened cement paste with $40 \%$ replacement by fly ash progressed slowly up to 12 months. However, these reactions were negligible from 12 to 24 months regardless of whether solution was injected.

- IAA-Ca(OH $)_{2}$ activated fly-ash particles shortly after injection. IWC did not contribute to activating these particles but accelerated cement hydration, which resulted in the activation of fly-ash particles.

The injection of saturated $\mathrm{Ca}(\mathrm{OH})_{2}$ solution from the age of 1 month was therefore effective in activating fly-ash particles, which directly resulted in the acceleration of the pozzolanic reaction of fly ash in hardened cement paste with $40 \%$ replacement by fly ash, although this effect was negligible from 12 to 24 months. Further effective methods need to be investigated to overcome this drawback. The chemical reactions in the hardened fly ash-cement paste/concrete internally activated by this injection should be studied from a thermodynamic point of view in future works to confirm the effectiveness of internal alkali activation.

\section{Compliance with ethical standards}

Conflict of interest The authors declare no conflict of interest.

Open Access This article is distributed under the terms of the Creative Commons Attribution 4.0 International License (http:// creativecommons.org/licenses/by/4.0/), which permits use, duplication, adaptation, distribution and reproduction in any medium or format, as long as you give appropriate credit to the original author(s) and the source, provide a link to the Creative Commons license and indicate if changes were made.

\section{References}

1. Hemalatha T, Ramaswamy A (2017) A review on fly ash characteristics: towards promoting high volume utilization in developing sustainable concrete. J Clean Product 147:546-559
2. McLellan BC, Williams RP, Lay J, van Riessen A, Corder GD (2011) Costs and carbon emissions for geopolymer pastes in comparison to ordinary Portland cement. J Clean Product 19(9-10):1080-1090

3. Mehta PK (2004) High-performance, high-volume fly ash concrete for sustainable development. In: Proceedings of international workshop on sustainable development and concrete technology, pp 3-14

4. Yang KH, Jung YB, Cho MS, Tae SH (2015) Effect of supplementary cementitious materials on reduction of $\mathrm{CO}_{2}$ emissions from concrete. J Clean Product 103:774-783

5. Hardjito D, Wallah SE, Sumajouw DMJ, Rangan BV (2004) On the development of fly ash-based geopolymer concrete. ACI Mater J 101(6):467-472

6. Nath P, Sarker P (2011) Effect of fly ash on the durability properties of high strength concrete. In: Proceedings of the twelfth East Asia-Pacific conference on structural engineering and construction, Proc Eng, vol 14, pp 1149-1156

7. Hooton RD (2015) Improved sustainability through durability design. In: Proceedings of international conference on sustainable structural concrete, La Plata, Argentina, pp 25-34

8. Lee CY, Lee HK, Lee KM (2003) Strength and microstructural characteristics of chemically activated fly ash-cement systems. Cem Concr Res 33(3):425-431

9. Puertas F, Martínez-Ramírez S, Alonso S, Vázquez T (2000) Alkali-activated fly ash/slag cements: strength behaviour and hydration products. Cem Concr Res 30(10):1625-1632

10. Fernández-Jiménez A, Palomo A (2005) Composition and microstructure of alkali activated fly ash binder: effect of activator. Cem Concr Res 35(10):1984-1992

11. Temuujin J, Williams RP, van Riessen A (2009) Effect of mechanical activation of fly ash on the properties of geopolymer cured at ambient temperature. J Mater Process Technol 209(12-13):5276-5280

12. De La Varga I, Castro J, Bentz D, Weiss J (2012) Application of internal curing for mixtures containing high volumes of fly ash. Cem Concr Compos 34(9):1001-1008

13. Nukushina T, Meddah MS, Seiki S, Sato R (2009) Experimental investigation on mechanical performance of concrete containing fly ash enhanced by internal curing with porous ceramic. In: Proceedings of the 11th annual International Federation for Structural Concrete (fib) symposium, London, UK

14. Bui PT, Ogawa Y, Doi N, Kawai K, Sato R (2015) Properties of steam-cured fly ash concrete using porous ceramic waste aggregate. In: Proceedings of the 13th international conference on recent advances in concrete technology and sustainability issues, Ottawa, Canada, pp 323-336

15. Bui PT, Muragishi Y, Ogawa Y, Kawai K, Sato R (2015) Effects of porous ceramic waste aggregate as an internal curing agent on steam-cured high strength fly ash concrete. In: Proceedings of the international conference on sustainable structural concrete, La Plata, Argentina, pp 66-76

16. Bui PT, Ogawa Y, Nakarai K, Kawai K (2015) A study on pozzolanic reaction of fly ash cement paste activated by an injection of alkali solution. Constr Build Mater 94:28-34

17. Bui PT, Ogawa Y, Nakarai K, Kawai K (2016) Effect of internal alkali activation on pozzolanic reaction of lowcalcium fly ash cement paste. Mater Struct 49:3039-3053 
18. Fan Y, Yin S, Wen Z, Zhong J (1999) Activation of fly ash and its effects on cement properties. Cem Concr Res 29(4):467-472

19. Ryu GS, Lee YB, Koh KT, Chung YS (2013) The mechanical properties of fly ash-based geopolymer concrete with alkaline activators. Constr Build Mater 47:409-418

20. Sakai E, Miyahara S, Ohsawa S, Lee SH, Daimon M (2005) Hydration of fly ash cement. Cem Concr Res 35(6):1135-1140

21. Ohsawa S, Asaga K, Goto S, Daimon M (1985) Quantitative determination of fly ash in the hydrated fly ash-CaSO${ }_{4} \cdot \mathrm{H}_{2} \mathrm{O}$ $\mathrm{Ca}(\mathrm{OH})_{2}$ system. Cem Concr Res 15:357-366

22. Termkhajornkit P, Nawa T, Kurumisawa K (2006) Effect of water curing conditions on the hydration degree and compressive strengths of fly ash-cement paste. Cem Concr Compos 28(9):781-789

23. Lam L, Wong YL, Poon CS (2000) Degree of hydration and gel/space ratio of high-volume fly ash/cement systems. Cem Concr Res 30(5):747-756

24. Bui PT, Ogawa Y, Nakarai K, Kawai K, Sato R (2017) Internal curing of class-F fly-ash concrete using high- volume roof-tile waste aggregate. Mater Struct 50:203. https://doi.org/10.1617/s11527-017-1073-Z

25. Zhang YM, Sun W, Yan HD (2000) Hydration of highvolume fly ash cement pastes. Cem Concr Compos 22(6): $445-452$

26. Wang A, Zhang C, Sun W (2004) Fly ash effects: II. The active effect of fly ash. Cem Concr Res 34(11):2057-2060

27. Chindaprasirt P, Jaturapitakkul C, Sinsiri T (2007) Effect of fly ash fineness on microstructure of blended cement paste. Constr Build Mater 21(7):1534-1541

28. Bijen J (1996) Benefits of slag and fly ash. Constr Build Mater 10(5):309-314

29. Chindaprasirt P, Jaturapitakkul C, Sinsiri T (2005) Effect of fly ash fineness on compressive strength and pore size of blended cement paste. Cem Concr Compos 27(4):425-428

30. Yamamoto T, Kanazu T (2007) Experimental explanation of compacting effect on hydration phases and strength development mechanism derived from pozzolanic reaction of fly ash. J JSCE 63-1:52-65 